\title{
ПИКОСЕКУНДНАЯ СПЕКТРОСКОПИЯ КОМПЛЕКСОВ ПОРФИРИНОВ С ПЕРЕХОДНЫМИ МЕТАЛЛАМИ IV ПЕРИОДА ПЕРИОДИЧЕСКОЙ СИСТЕМЫ ЭЛЕМЕНТОВ
}

Значительный интерес для координационной химии, фотохимии и фотобиологии представляет установление путей и механизма внутримолекулярного размена энергии возбуждения в комплексах порфиринов с ионами переходных металлов, к числу которых относится гем крови. С 1977 года нами ведутся систематические исследования названных соединений методом пикосекундной абсорбционной спектроскопии в целях обнаружения спектров поглощения низших возбужденных электронных состояний и изучения их спектрально-кинетических характеристик $\left[{ }^{1-4}\right]$. Близкие к нашим результаты для некоторых аналогичных комплексов были получены в работах П. М. Рентцеписа с сотрудниками $\left[{ }^{5,6}\right]$.

В настоящем сообщении представлены новые данные по измерению спектров поглощения и времен жизни возбужденных электронных состояний в комплексах порфиринов с $d$-элементами IV периода Периодической системы элементов Менделеева.

Объектами исследования выбраны комплексы порфиринов с ионами $\mathrm{Cr}(\mathrm{III}), \mathrm{Mn}(\mathrm{III})$, Fe(II), Fe(III), Co(II), Ni(II), Cu(II), чтобы обсудить влияние физических характеристик металла (степень окисления, спин, электронная конфигурация) на параметры внутримолекулярной энергетики. Әкспериментальная установка пикосекундной абсорбционной спектроскопии с временным разрешением 8 nc описана в [ ${ }^{1}$ ]. Полученные нами результаты можно разделить на три группы.

1. Фотовозбуждение растворов всех перечисленных-выше соединений лазерным импульсом длительностью $\tau_{\text {возб }}=6-8$ nс приводит к появлению короткоживущего поглощения, спектр которого очень близок к спектру триплет-триплетного поглощения порфиринов и металлопорфиринов, содержащих заполненные $d$-оболочки, $\mathrm{Zn}(\mathrm{II})$ - тетрафенилпорфина, например. При этом если для одних соединений удавалось измерить время жизни $\tau_{T}$ состояния, ответственного за это поглощение, то для других нет - длительность наблюдаемого процесса была короче

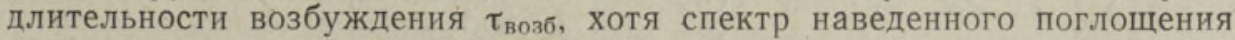
надежно регистрировался с временем жизни, равным длительности -импульса фотовозбуждения. На рис. 1,a и 2 показаны спектры поглощения для двух таких случаев. Времена жизни возбужденных состояний $\tau_{T}$ приведены в таблице, причем в тех случаях, когда $\tau_{T}$ соизмеримо с

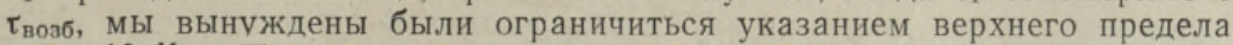
$\tau_{T}<10^{-11} c$. При установлении природы электронного уровня, ответственного за поглощение, необходимо указать на следующее. Для комплексов, у которых все $d$-электроны металла спарены, основное состояние - синглетное и имеются множества синглетных и триплетных уровней. В таких комплексах наблюдаются обычные триплет-триплетные спектры. Если же комплекс имеет один неспаренный $d$-электрон или 


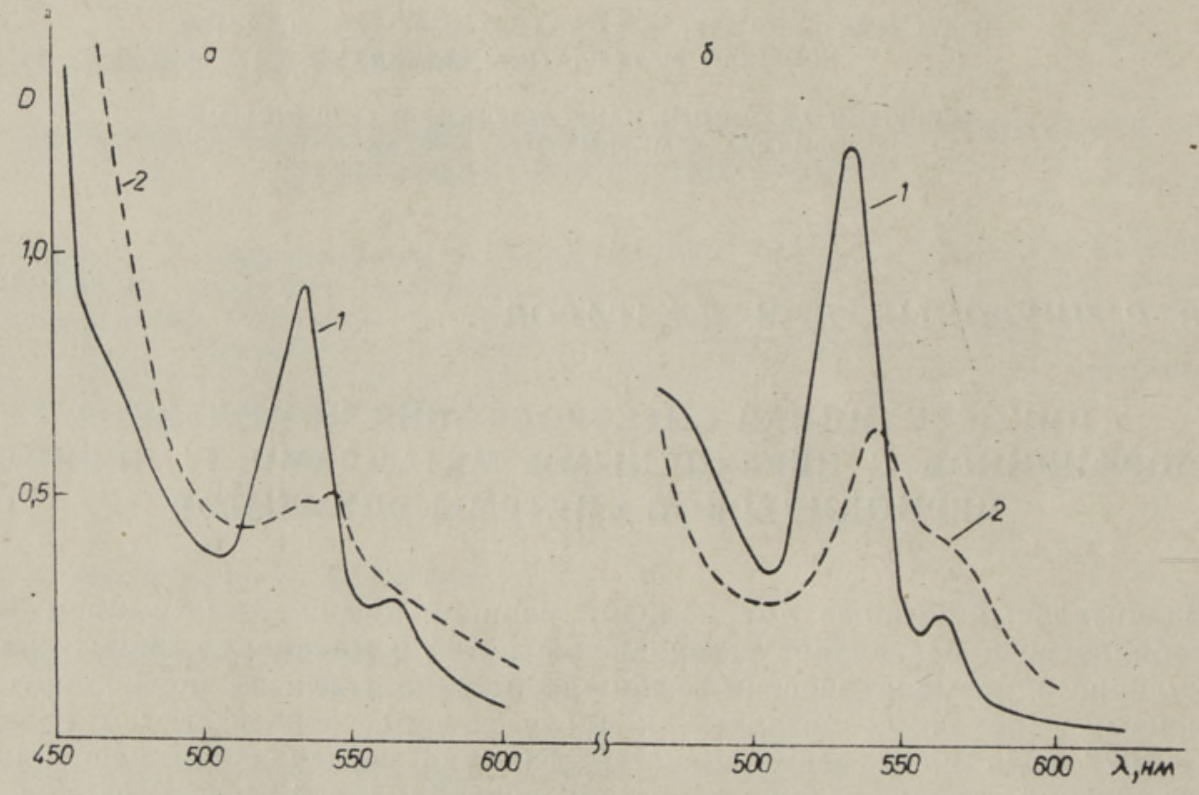

Рис. 1. Спектры поглощения $\mathrm{Fe}$ (II)-(пиридин) 2 - тетрафенилпорфина в пиридине в основном синглетном ${ }^{1} S_{0}$-состоянии (кривые 1 ); в возбужденном триплетном ${ }^{3} T_{1}$-состоянии (кривая 2 на рис. $a$ ), нулевая задержка по отношению к возбуждению, $\tau_{T}<10^{-11} c$; после отщепления пиридина (кривая 2 на рис. б), задержка 20 nc. Время жизни 150 nc. Абсолютная погрешность измерения короткоживущих спектров составляет $0,04-0,05$ ед. оптической плотности.

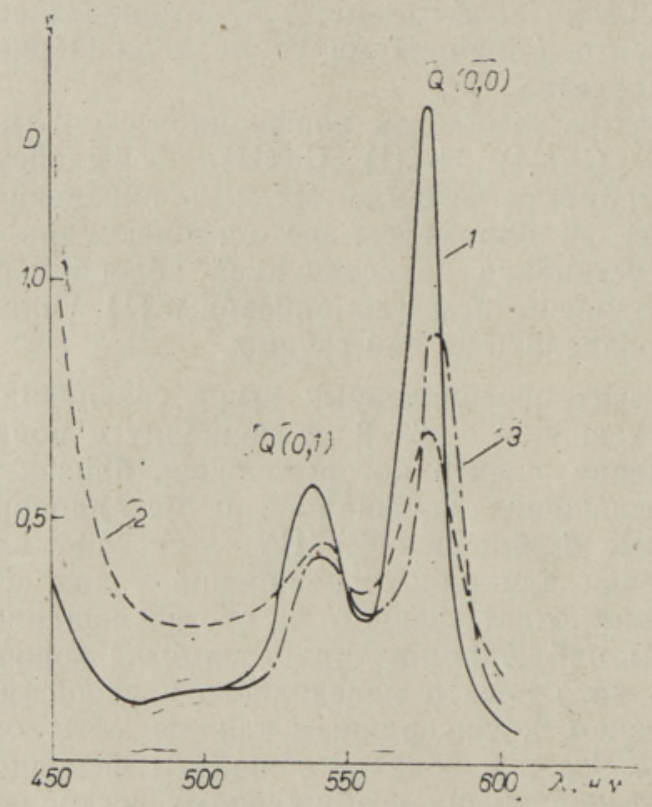

Рис. 2. Спектры поглощения $\mathrm{Cr}$ (III)(фенол) - октаэтилпорфина в толуоле в основном ${ }^{4} S_{0}$-состоянии (кривая 1 ); в возбужденном $2,4,6 T_{1}$-состоянии (кривая 2), нулевая задержка по отношению к возбуждению, $\tau_{T}<$ $\left\langle 10^{-11} c\right.$; в $T_{d}$-состоянин (кривая 3 ), задержка $15 n c, \tau_{d}=30$ nc. Абсолютная погрешность измерения возбужденных состояний составляет $0,03-$ 0,05 ед. оптической плотности. Часть поглощения в области полос $Q(0,0)$ и $Q(0,1)$ вызвана поглощением в основном состоянии из-за неполной конверсии в возбужденные состояния.

более, то обменное взаимодействие $d$-электронов с $\pi$-электронами собственно порфирина приводит к усложнению системы уровней энергии. Не останавливаясь на каждом комплексе отдельно (подробное их рассмотрение можно найти в $\left.\left[{ }^{7}\right]\right)$, ограничимся лишь указанием в таблице значений спина металла и обозначением основного ${ }^{i} S_{0}$ и «трипмультиплетного» состояния ${ }^{i} T_{1}$, ответственного за спектр коротқоживущего по- 


\begin{tabular}{|c|c|c|c|c|c|c|}
\hline Соединение & $\begin{array}{l}\text { Раство- } \\
\text { ритель }\end{array}$ & $\begin{array}{c}\text { Элект- } \\
\text { ронная } \\
\text { конфн- } \\
\text { гура- } \\
\text { ция }\end{array}$ & Спин & $\begin{array}{c}\text { Основ- } \\
\text { ное со- } \\
\text { стояние } \\
{ }^{i} S_{0}\end{array}$ & $\begin{array}{c}\text { Воз- } \\
\text { буж- } \\
\text { денное } \\
\text { состоя- } \\
\text { ние } \\
{ }^{i} T_{1}\end{array}$ & $\begin{array}{c}\text { Время жизни } \\
\text { возбужден- } \\
\text { ного состоя- } \\
\text { ния } \tau_{T}, c\end{array}$ \\
\hline $\mathrm{Cr}(\mathrm{III})$ - октаэтилпорфин* & $\begin{array}{l}\text { Метанол十 } \\
\text { пиридин }\end{array}$ & $d^{3}$ & $3 / 2$ & ${ }^{4} S_{0}$ & ${ }^{2,4,6} T_{1}$ & $2 \cdot 10^{-7}$ \\
\hline $\mathrm{Cr}$ (III) - октаэтилпорфин & Толуол & $d^{3}$ & $3 / 2$ & ${ }^{4} S_{0}$ & $2,4,6 T_{1}$ & $<10^{-11}$ \\
\hline Mn(III) - мезопорфирнн & & $d^{4}$ & 2 & ${ }^{5} S_{0}$ & ${ }^{3,5,7} T_{1}$ & $5,5 \cdot 10^{-11}$ \\
\hline $\mathrm{Fe}(\mathrm{II})$ - тетрафенилпорфин & Бензол & $d^{6}$ & 2 & ${ }^{5} S_{0}$ & ${ }^{3,5,7} T_{1}$ & $2,5 \cdot 10^{-11}$ \\
\hline $\begin{array}{l}\mathrm{Fe}(\mathrm{II})-(\text { пиридин })_{2}-\text { тетра- } \\
\text { фенилпорфин }\end{array}$ & Пиридин & $d^{6}$ & 0 & ${ }^{1} S_{0}$ & ${ }^{3} T_{1}$ & $<10^{-11}$ \\
\hline $\begin{array}{l}\mathrm{Co}(\text { II) - тетрафенилпорфин } \\
\mathrm{Ni}(\text { II) - дейтеропорфи- }\end{array}$ & Бензол & $d^{7}$ & $1 / 2$ & ${ }^{2} S_{0}$ & ${ }^{2,4} T_{1}$ & $<10^{-11}$ \\
\hline рин** & Толуол & $d^{8}$ & 0 & ${ }^{1} S_{0}$ & ${ }^{3} T_{1}$ & $1,5 \cdot 10^{-11}$ \\
\hline $\mathrm{Ni}(\mathrm{II})$ - дейтеропорфирин & Пиридин & $d^{8}$ & 0 & ${ }^{1} S_{0}$ & ${ }^{3} T_{1}$ & $1,5 \cdot 10^{-11}$ \\
\hline $\begin{array}{c}\mathrm{Ni}(\mathrm{II}) \text { - (пиперидин })_{2}- \\
\text { дейтеропорфирин }\end{array}$ & Пиперидин & $d^{8}$ & 1 & ${ }^{3} S_{0}$ & ${ }^{1,3,5} T_{1}$ & $2 \cdot 10^{-11}$ \\
\hline $\mathrm{Cu}(\mathrm{II})$ - мезопорфирин* & Толуол & $d^{9}$ & $1 / 2$ & ${ }^{2} S_{0}$ & ${ }^{2,4} T_{1}$ & $7,5 \cdot 10^{-8}$ \\
\hline $\begin{array}{l}\mathrm{Cu}(\mathrm{II}) \text { - тетрафенилпор- } \\
\text { фин }^{*}\end{array}$ & " & $d^{9}$ & $1 / 2$ & ${ }^{2} S_{0}$ & ${ }^{2,4} T_{1}$ & $3,5 \cdot 10^{-8}$ \\
\hline $\mathrm{Cu}$ (II) - тетрафенилпорфин & Пириднн & $d^{9}$ & $1 / 2$ & ${ }^{2} S_{0}$ & ${ }^{2,4} T_{1}$ & $5 \cdot 10^{-11}$ \\
\hline $\mathrm{Cu}(\mathrm{II})$ - мезопорфирин & $"$ & $d^{9}$ & $1 / 2$ & ${ }^{2} S_{0}$ & ${ }^{2,4} T_{1}$ & $5 \cdot 10^{-11}$ \\
\hline
\end{tabular}

* Измерения выполнены методом наносекундного флеші-фотолиза П. Н. Дылько. ** В [] для $\mathrm{Ni}(\mathrm{II})$ - протопорфирнна получены аналогичные результаты.

глощения, где $i$ - мультиплетность состояния. Расщепление ${ }^{i} T_{1}$-уровня на компоненты, расстояние между которыми составляет от десятков до сотен $c M^{-1}\left[{ }^{7}\right]$, определяется обменным интегралом $d-\pi$, а заселенность компонент - больцмановским фактором.

Причиной сверхкоротких времен жизни $\tau_{T}$ для исследованных комплексов является наличие низколежащих уровней иной природы, чем $\pi \pi^{*}$, а именно $d$-уровней металла или уровней состояний с переносом заряда между $d$ - и л-орбиталями. Дополнительное возмущение может вносить также смешивание незаполненных $l_{g}\left(\pi^{*}\right)$-орбиталей порфирина и $d_{л}$-орбиталей металла. Подробное теоретическое обсуждение влияния взаимного расположения $\pi-\pi^{*}$ - и $d$-орбиталей дано в $\left[{ }^{7}\right]$.

2. Для комплексов порфиринов с $\mathrm{Ni}(\mathrm{II}), \mathrm{Cr}(\mathrm{III})$ и $\mathrm{Co}(\mathrm{II})$ короткоживущее поглощение сменяется поглощением бо́льшей длительности $\tau_{d}-2,5 \cdot 10^{-10}, 3 \cdot 10^{-11}$ и $>1 \cdot 10^{-9} c$ соответственно. Причем эти спектры резко отличны от спектров предшествующей формы и близки по форме к спектрам поглощения (см. рис. 2) в основном состоянии, но сдвинуты спектрально. Эти спектры мы интерпретируем как поглощение в состоянии $T_{d}$ с возбужденной $d^{8}$-конфигурацией, которая реализуется в результате внутримолекулярного переноса энергии из ${ }^{i} T_{1}$-состояния $\pi \pi^{*}$-природы на $d$-уровень комплекса, который связан преимущественно с возбуждением $d$-электрона на высшую незаполненную $d$-орбиталь.

3. В комплексах порфиринов с дополнительными азотистыми аксиальными лигандами, $\mathrm{Fe}(\mathrm{II})$ с пиридином и $\mathrm{Ni}$ (II) с пиперидином, было обнаружено обратимое фотоотщепление этих лигандов, на что указывает появление спектров, соответствующих металлокомплексу без лиганда (см. рис. $1, б)$. При этом было зарегистрировано электронное состояние, предшествующее состоянию с фотоотщепленными лигандами, спектр поглощения этого состояния близок к спектру триплет-триплетного поглощения.

Таким образом, в результате проведенных исследований мы распо- 
лагаем спектрально-временными характеристиками возбужденных электронных состояний комплексов порфиринов с ионами переходных металлов. Мы полагаем, что эта информация может оказаться необходимой при выяснении механизма фотохимических реакций, протекающих с участием этих соединений.

\title{
ЛИТЕРАТУРА
}

1. Джагаров Б. М., Тиминский Ю. В., Чирвоный В. С., Гуринов и ч Г. П., Докл. АН СССР, 247, № 3, $728-731$ (1979).

2. Чи рвоный В. С., Д жагаров Б. М., Тимин икий Ю. В., Изв. АН СССР, сер. физ., 44, № 4, 868-872 (1980).

3. Chirvonyi, V. S., Dzhagarov, B. M., Timinskii, Yu. V., Gurinov i c h, G. P., Chem. Phys. Lett., 70. № 1, 79-83 (1980).

4. Чирвоный В. С., Джагаров Б. М., Шульга А. М., Гуринович Г. П., Докл. АН СССР, 259, № 5. 1256-1260 (1981).

5. Kobayashi, T., Huppert, D., Straub, K. D., Rentzepis, P. M., J. Chem. Phys., 70, № 4, 1720-1726 (1979).

6. Kobayashi, T., Straub, K. D., Rentzepis, P. M., Photochem. Photobiol., 29, 925-931 (1979).

7. Gouterman, M., In: The Porphyrins (ed. D. Dolphin), III, Academic Press, New York, 1978, p. $1-165$.

\author{
Институт физики \\ Академии наук Белорусской ССР
}

\author{
V. S. TSIRVONOI, B. M. DZAGAROV
}

\section{ELEMENTIDE PERIOODILISUSE SUSTEEMI IV PERIOODI POOLMETALLE SISALDAVATE PORFURIINIDE PIKOSEKUNDSPEKTROSKOOPIA}

Pikosekundspektroskoopia neeldumismeetodil on saadud porfüriini metallikomplekside ergastatud elektrono!ekute neeldumisspektrid ja eluead. Eluead sõltuvad tsentraalse metalliiooni ning aksiaalse ligandi iseloomust ning on vahemikus $10^{-7}$ kuni $10^{-11} \mathrm{~s}$ või lühemad. On avastatud mõnede $\mathrm{Ni}$ (II) ja $\mathrm{Fe}$ (II) porfüriinide aksiaalsete ligandide fotodissotsiatsioon. Lühidalt on kirjeldatud elektronenergia molekulisisest relaksatsioonimehhanismi.

V. S. CHIRVONYI, B. M. DZHAGAROV

\section{PICOSECOND SPECTROSCOPY OF PORPHYRIN COMPLEXES WITH TRANSITION METALS FROM ROW IV OF THE PERIODIC TABLE OF ELEMENTS}

Picosecond absorption spectroscopy was used to find the excited state absorption spectra in $\mathrm{Cr}(\mathrm{III})_{-}, \mathrm{Mn}(\mathrm{III})_{-}, \mathrm{Fe}(\mathrm{II})_{-}, \mathrm{Fe}(\mathrm{III})_{-}, \mathrm{Ni}(\mathrm{II})_{-}$, and $\mathrm{Cu}(\mathrm{II})_{-}$porphyrins. Picosecond and nanosecond measurements of the kinetics of transient intermediates helped to determine the lifetimes of the lowest excited state. The lifetimes, depending on the nature of the central ion of the metal and axial ligand, covered the time interval from $10^{-7} \mathrm{~s}$ to $10^{-11} \mathrm{~s}$ and even shorter. In some $\mathrm{Ni}(\mathrm{II})$ - and $\mathrm{Fe}(\mathrm{II})$ - porphyrins axial ligand photodissociation was found. The mechanism of the intramolecular energy relaxation is briefly discussed. 